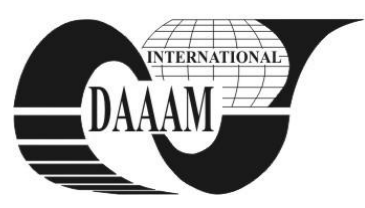

Annals of DAAAM for 2012 \& Proceedings of the 23rd International DAAAM Symposium, Volume 23, No.1, ISSN 2304-1382 ISBN 978-3-901509-91-9, CDROM version, Ed. B. Katalinic, Published by DAAAM International, Vienna, Austria, EU, 2012 Make Harmony between Technology and Nature, and Your Mind will Fly Free as a Bird Annals \& Proceedings of DAAAM International 2012

\title{
IMPORTANCE OF EXPERIMENTAL RESEARCH IN THE DESIGN OF STRUCTURES
}

\author{
BRNIC, J[osip]; TURKALJ, G[oran] \& VUKELIC, G[oran]
}

\begin{abstract}
The problems that can be solved encompass practically all fields of human activity, e.g. they are related to constructions like bridges, ships, airplanes, machines, etc., or to transport, refinement or other engineering systems, or in general, to design or manufacturing of the mentioned constructions and systems. However, recent design and manufacture are based on numerical analysis supported by highly capacitive computers. It is generally known that the design is considered as the best one, if it is based on experimental data. In accordance with this, experimental investigations related to material properties of St 44-2 non alloy structural steel were performed. Based on these studies, the paper presents data on the tensile strength, 0.2 offset yield strength, creep behavior and Charpy impact energy.
\end{abstract}

Keywords: material properties, high temperature, creep behavior, steel St 44-2

\section{INTRODUCTION}

\subsection{Modern design of structures}

Recent design of structures requires a numerical analysis of structures, life assessment and design optimization. Also, the previously mentioned design procedure requires the support of highly capacitive computers. In present time both stress and strain analysis of structure are made using finite element method (FEM). The most distinctive feature of this method that separates it from others is the division of a given area (domain) into a set of simple subareas using which the imagined or real structure can be described / defined [1]. In accordance with the challenge that structure should be designed and produced in such a way that undesirable failures do not occur during the design life of the structure, the designer should take account about all of possible failures which can arise during the mentioned service life [2]. As it is well known, the following list of failure modes commonly observed in engineering practice may be given: force and / or temperature induced elastic deformation, yielding, fatigue, corrosion, creep, etc. [3]. In a failure analysis, the knowledge of the nature and magnitude of the stress that occurs in a failed component can be a significant aspect of the investigation [4]. Talking about optimization of structure, it is understand that all of optimization elements need to be included e.g. sizes optimization, material, shape and layout optimization [5]. However, the optimization procedure can be more successful if the input data on material behavior are experimentally obtained data.

\subsection{Recent published work related to the material discussed}

Although the considered material is widely used, only little recent published papers related to it can be found in literature. Some of them are listed below. An investigation on the static and fatigue strength behavior of a composite sandwich system which consists of a lightweight concrete core sandwiched in between two steel plates made of St 44-2 steel in presented in Ref. [6]. Further, the new method for forecasting the yield point and the ultimate tensile strength for steel can be found in [7].

In this investigation the mentioned parameters are calculated basing on the chemical composition and technological factors of steel manufacturing. An approach is developed to make prediction of these properties possible. In Ref. [8] some researches/tests conducted on slender circular tubular columns filled with normal and high strength concrete subjected to eccentric axial load are desribed. The experimental ultimate load of each test was compared with the design loads from Eurocode 4. The cold formed and welded steel tubes were made of St 44-2 steel. Investigations presented in this paper provide new information on the behavior of steel St 44-2 according to its material properties and creep resistance at different temperatures. Sometimes it is useful to gain insight into the behavior of the same or similar materials, to consider certain works [9-11].

\section{EXPERIMENTAL PROGRAM}

Material under consideration was non-alloy St 44-2 structural steel with the chemical composition given in Tab 1. in mass (\%).

\begin{tabular}{|c|c|c|c|c|c|}
\hline $\mathrm{C}$ & $\mathrm{Si}$ & $\mathrm{Mn}$ & $\mathrm{P}$ & $\mathrm{S}$ & $\mathrm{Ni}$ \\
\hline 0.08 & 0.22 & 0.57 & 0.025 & 0.017 & 0.14 \\
\hline $\mathrm{Cr}$ & $\mathrm{Mo}$ & $\mathrm{Cu}$ & $\mathrm{Al}$ & Rest & - \\
\hline 0.1 & 0.02 & 0.5 & 0.002 & 98.326 & \\
\hline
\end{tabular}

Tab. 1. Chemical composition of St 44-2 in mass (\%).

Round $5 \mathrm{~mm}$ diameter test specimens were machined from the $18 \mathrm{~mm}$ diameter rod. Specimen dimensions were defined according to those specified in ASTM.

Test equipment used in this research included: 400 $\mathrm{kN}$ materials testing machine, macroextensometer, furnace, high temperature extensometer and Charpy impact machine. Mentioned equipment as well as test specimen are presented in Fig. 1.

Standards according to which samples were prepared and test procedures were performed are defined in Ref. [12]. 


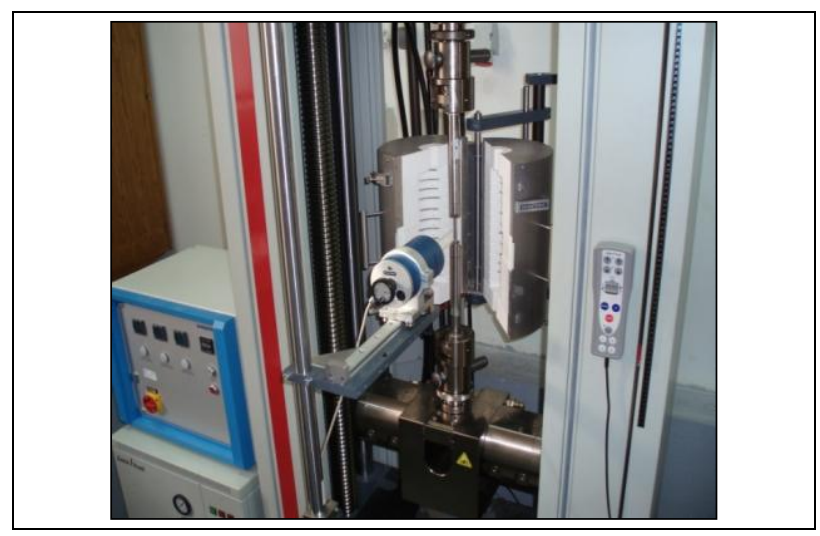

a)

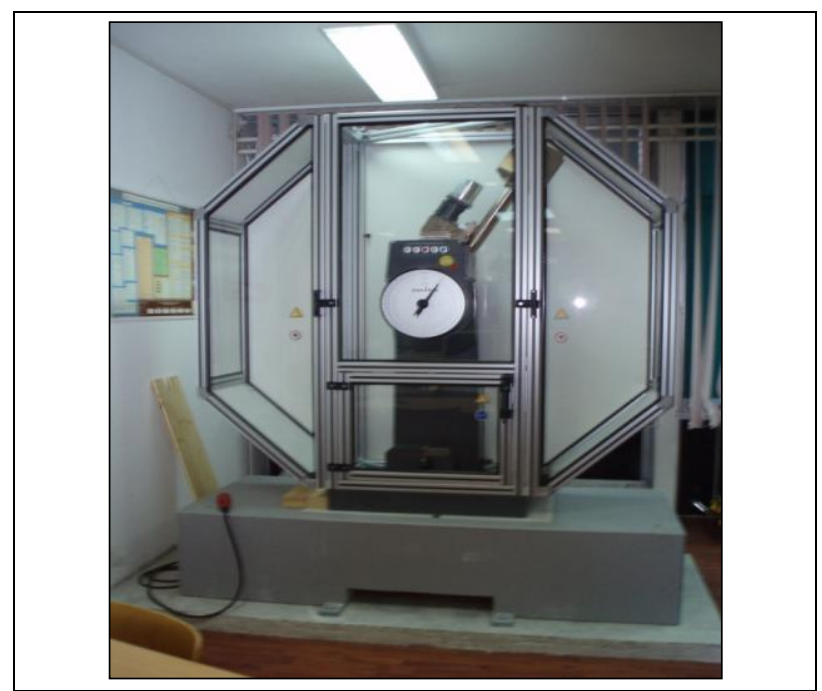

b)

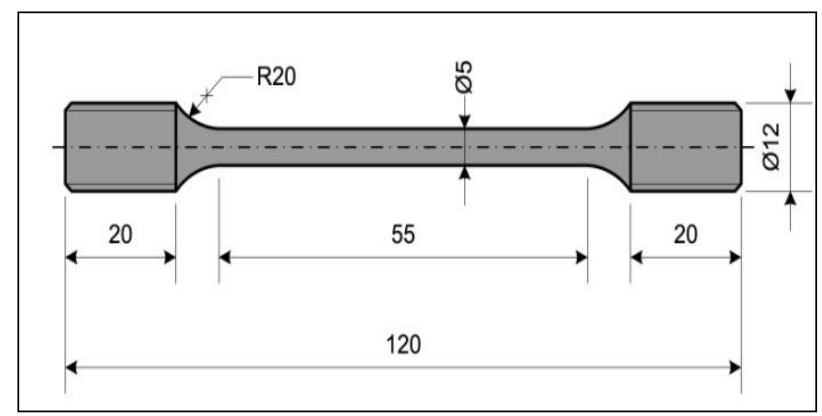

c)

Fig. 1. Equipment. a) Furnace and high temp. extensometer. b) Charpy impact machine. c) Test specimen (mm)

\section{EXPERIMENTAL RESULTS AND DISCUSSION}

\subsection{Engineering stress-strain diagrams}

Material properties of considered material are presented in the form of engineering stress-strain diagrams, Fig. 2.

According to performed tests and engineering stressstrain diagrams presented in Fig. 2, numerical data of material properties are also given in Tab 2.

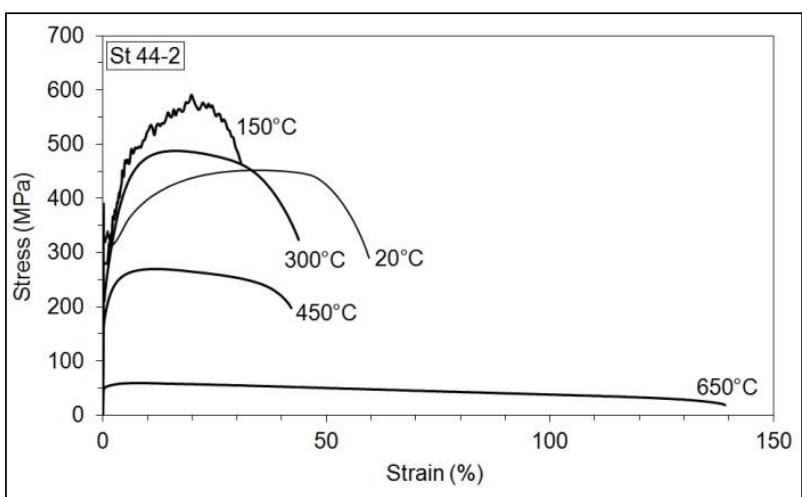

Fig. 2. Stress vs. strain of St 44-2 steel at different temperatures

\begin{tabular}{|c|c|c|c|}
\hline $\begin{array}{c}\text { Temperature } \\
\left({ }^{0} \mathrm{C}\right)\end{array}$ & $\begin{array}{c}\sigma_{\mathrm{m}} \\
(\mathrm{MPa})\end{array}$ & $\begin{array}{c}\sigma_{0.2} \\
(\mathrm{MPa})\end{array}$ & $\begin{array}{c}\mathrm{E} \\
(\mathrm{GPa})\end{array}$ \\
\hline 20 & 452 & 322.7 & 211 \\
\hline 150 & 590.8 & 280 & 196 \\
\hline 300 & 488 & 211.6 & 183.4 \\
\hline 450 & 270 & 172.6 & 157 \\
\hline 650 & 59.8 & 48.3 & 65 \\
\hline
\end{tabular}

Tab. 2. Material properties of St 44-2. $\left(\sigma_{\mathrm{m}}\right.$ - ultimate tensile strength, $\sigma_{0.2}-0.2$ offset yield strength, $E$ - modulus of elasticity)

\subsection{Creep behavior}

Several creep tests were performed. Selected stress levels as well as selected temperature are visible from presented creep curves, Fig. 3.

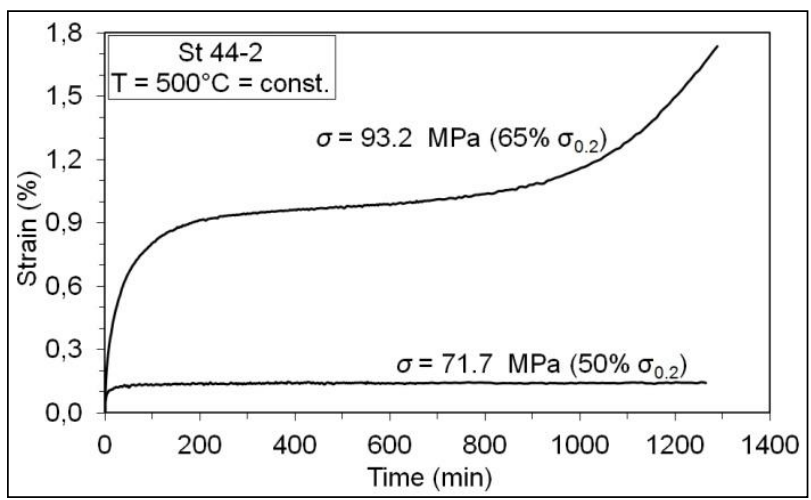

Fig. 3. Creep behavior of St $44-2$ steel at temperature of $500^{\circ} \mathrm{C}$

According to presented experimental results, it is visible that ultimate tensile strength slowly increases with temperature rise till $250^{\circ} \mathrm{C}-300^{\circ} \mathrm{C}$ and after this temperature it decreases with temperature increase. 0.2 offset yield strength constantly decreases with temperature increase.

Modulus of elasticity has a value of $211 \mathrm{GPa}$ at temperature of $20^{\circ} \mathrm{C}$ and $65 \mathrm{GPa}$ at $650^{\circ} \mathrm{C}$. Investigations has showed tat this material is creep resistant at temperature of $400^{\circ} \mathrm{C}$ (not presented in this paper), and it is relatively creep resistant at temperature of $500^{\circ} \mathrm{C}$ if stress level does not exceed $50 \%$ of yield point. Investigations regarding to material creep behavior are quite expensive, because of special equipment that is needed. In any case the knowledge about material creep behavior is of importance for designer who is involved in structure design that operates in similar environmental conditions. In accordance with all what was said, an atempt to model the behavior of creep is noteworthy. Creep behavior represented by creep curve can be 
modeled using some of existing formulas or using some of rheological models [13]. Some of rheological models and the corresponding equations for determining the deformations are given in the following part of this paper. Burgrs model is presented in Fig.4.

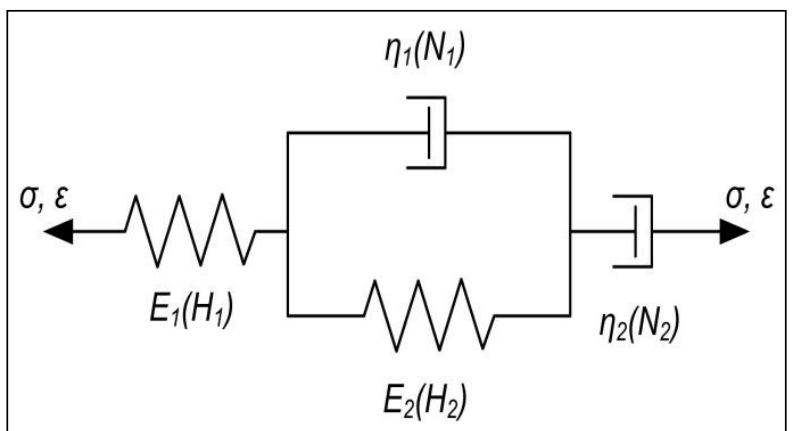

Fig. 4.Burgers model

$\boldsymbol{H}$ - Hooke's model, $\boldsymbol{N}$ - Newton's model, $\boldsymbol{E}_{1}-$ modulus of elasticity, $\boldsymbol{E}_{2}$ , $\boldsymbol{\eta}_{1}, \boldsymbol{\eta}_{2}$ - material parameters, $\boldsymbol{\sigma}$ - stress, $\boldsymbol{\varepsilon}$ - strain

For Burgers model the following equation is valid:

$$
\varepsilon(t)=\sigma\left[\frac{1}{E_{1}}+\frac{1}{E_{2}}\left(1-e^{\left(-E_{2} / \eta_{1}\right) t}\right)+\frac{t}{\eta_{2}}\right],
$$

where $\varepsilon(t), \sigma, E_{1}, t$, are strain, stress, modulus of elasticity and time related to the considered creep curve, while $E_{2}$, $\eta_{1}$ and $\eta_{2}$ are parameters.

Standard Linear Solid Model is presented in Fig.5.

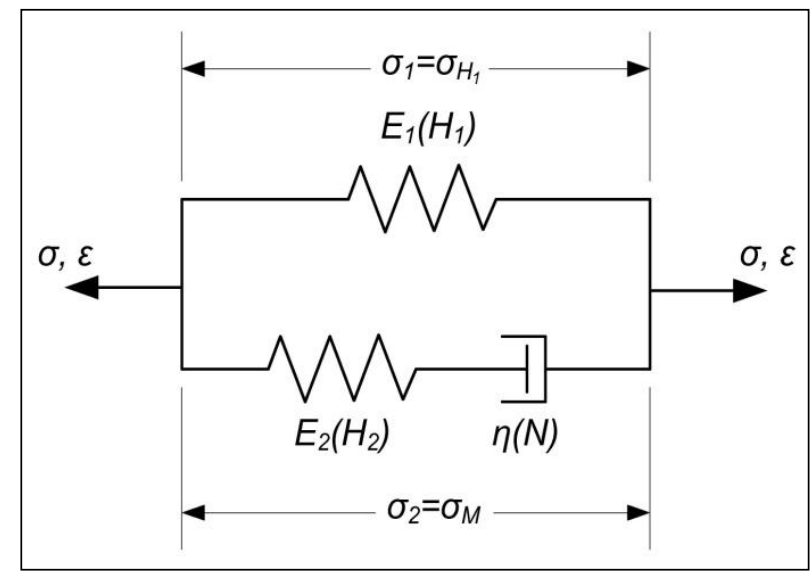

Fig. 5. Standard Linear solid (SLS) model

$\boldsymbol{H}$ - Hooke's model; $\boldsymbol{M}$ - Maxwell model, $\boldsymbol{N}$ - Newton's model; $\boldsymbol{E}_{1}-$ the modulus of elasticity; $\boldsymbol{E}_{2}, \boldsymbol{\eta}_{1}, \boldsymbol{\eta}_{2}$ - material parameters, $\boldsymbol{\sigma}$ - stress, $\boldsymbol{\varepsilon}$ strain

For SLS model the following equation is valid:

$$
\varepsilon(t)=\frac{\sigma}{E_{1}}+\sigma\left(\frac{1}{E_{1}+E_{2}}-\frac{1}{E_{1}}\right) \cdot e^{-\frac{E_{1} E_{2} t}{\left(E_{1}+E_{2}\right) \eta}},
$$

where $\varepsilon(t), \sigma$ and $t$ are strain, stress and time related to the considered creep curve, while $E_{2}, E_{2}$ and $\eta$ are parameters.

Burgers model may be applicable for modeling primary and secondary stage of creep curve but it is more suitable for secondary stage of creep. SLS model is quite good for modeling primary stage of creeo ecpecialy when this stage is significantly parabolic. Using the proposed models, the creep cuve presented the material creep behavior at 71.7 MPa shown in Fig. 3, is now modeled. This simulation is shown in Fig. 6.

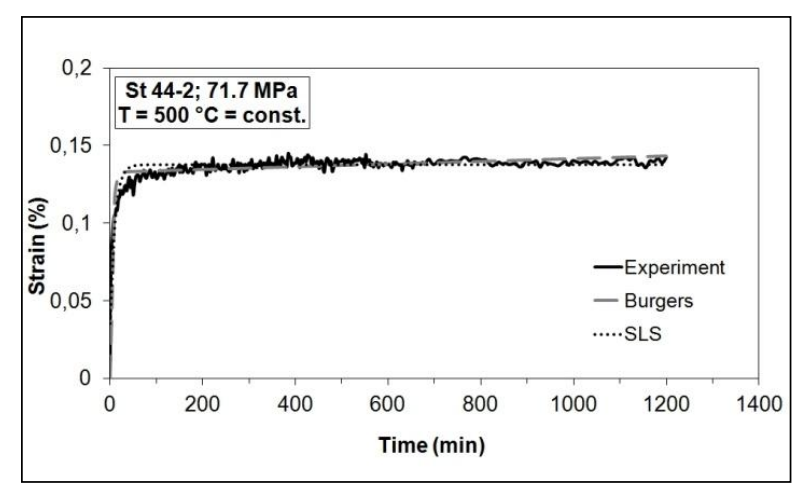

Fig. 6. Creep curve simulation: material St 44-2, $\sigma=71.7 \mathrm{MPa}, T=$ $500^{\circ} \mathrm{C}, t=1200 \mathrm{~min}$, Burgers model and SLS model

According to experimentally obtained creep curve, presented in Fig. 6, it is visible that the graeter part of the creep curve belongs to the secondary stage of the creep. In that way Burgers model may be quite suitable for creep modeling.

\subsection{Charpy impact energy}

It is well known that two key mechanical properties are of significance in design proces. One of them is yield strength which is used to design structure against plastic deformation, and second one is fracture toughness which is used to design structure against fracture. A discipline underlying design against fracture is usually described as Fracture Mechanics. $K_{\text {Ic }}$, called fracture toughness, was introduced to define the nominal stress at which fracture takes place. In general, fracture toughness may be treated as a measure of material resistance against crack propagation or it is a quantitative way of expressing a material's resistance to brittle fracture when a crack is present. When material has a large value of fracture toughness it will probably undergo ductile fracture, while material with low fracture toughness will undergo to britle fracture. Also, fracture toughness is an indication of the amount of stress required to propagate a preexisting flaw. Flaws may appear as cracks, weld defects, design discontinuities, voids, metallurgical inclusions, or some combination thereof. Because of the reason that designer can never be sure that a material is flaw free, it is possible to assume that a flaw will be present and use the linear elastic fracture mechanics (LEFM) approach to design critical engineering components.

A parameter called the stress-intensity factor $(K)$ is used to determine the fracture toughness of material. Mode I of crack opening represents the case in which the crack plane is normal to the line of largest tensile loading. This is the most commonly encountered mode in engineering practice. In this case the stress intensity factor is designated as $\mathrm{K}_{\mathrm{I}}$. Once the tickness of the specimens exceeds the critical dimension, the value of $\mathrm{K}_{\mathrm{I}}$ becomes relatively constant and this value is called fracture toughness and designates as $\mathrm{K}_{\mathrm{Ic}}$, i.e. plane strain fracture toughness. It can be measured by a number of standard tests [14]. Fracture toughness is the most useful 
material property in the mentioned design against fracture, but there are also other tests that provide fracture resistance measurement. An impact test, widely used in ferrous metals and plastics industry, is test performed by Charpy pendulum impact machine shown in Fig. 1b. The notch acuity, the temperatures, etc., used in this test does not have to be representative for conditions in which many materials are used. In that way the results of Charpy impact tests can not be used directly to predict in-service behavior of the material and its failure characteristics. Although some diffulties with the application results on the basis of Charpy tests exixt, measurements of $\mathrm{K}_{\mathrm{Ic}}$ on the basis of standard test involve the use of large specimens which are difficult to excise from operating structural component. So, some assessment of fracture toughness based on Charpy tests may be reasonable. Using Charpy tests impact energy of the material will be measured. In cases where the real tests are performed that as a result can be obtained a single value of fracture toughness or a resistance curve where some of fracture toughness parameter $(K, J, \ldots)$ is ploted against crack extension. Standards regulate the shape as well as dimensions of specimens. As it is well known, when around the tip of the crak plastic zone is discernivle then linear elastic plastic theory can not be applied. In that case, other parameters representing fracture toughness are needed, for example $J$ - integral, [15]. Engineering estimates of $\mathrm{K}_{\mathrm{Ic}}$ can be predicted or correlated using impact CVN data [16].

For this material, using Charpy impact machine, Charpy impact energy (CVN) of 210 (J) was measured at room temperature $\left(20^{\circ} \mathrm{C}\right)$. In accordance with Ref. [17], assessment of fracture toughness based on Charpy impact energy can be done by Roberts-Newton equation:

$$
\mathrm{K}_{\mathrm{Ic}}=8.47(\mathrm{CVN})^{0.63} \text {. }
$$

This relation is valid regardless of the temperature. On the basis of given equation, fracture toughness of $245.97 \mathrm{MPa} \sqrt{\mathrm{m}}$ is calculated. Also, aside of characterizing fracture toughness by stress intensity factor $K$, it can also be assessed, as it was said, using $J$ integral. Sometimes other expressions can be used but they are often limited to the area in which impact energy need to be placed.

\section{CONCLUSION}

Experimentally obtained data related to behavior of St 44-2 steel at room and elevated temperatures are presented. The mentioned data are: ultimate tensile strength, 0.2 offset yield strength, creep behavior and Charpy impact energy. It can be said that this steel is characterized by good strength. Also it is resistant to creep at $400^{\circ} \mathrm{C}$. At temperature of $500^{\circ} \mathrm{C}$ creep resistance is also good but the stress level must not exceed $50 \%$ of yield point at this temperatute. To be sure in the evaluation of some material properties or its behavior at presribed conditions, some more experiments need to be carried out. In this sense, there are plans of research regarding the determination of material characteristics at different temperatures as well as performing more tests related to creep behavior at different temperatures.
It would be useful to compare the results of the fracture toughness obtained by Charpy machine with those from real experiments.

\section{ACKNOWLEDGEMENTS}

The research presented in this paper was financially supported by the Ministry of Science, Education and Sport of the Republic of Croatia.

\section{REFERENCES}

[1] Reddy, J.N. (1993). An Introduction to the Finite Element Method, $2^{\text {nd }}$ ed., McGraw-Hill Inc., ISBN: 0070513554, New York

[2] Schijve, J. (2009). Fatigue of Structures and Materials, Springer Science + Business Media, ISBN: 0792370147, Delft

[3] Collins, J.A. (1993). Failure of Materials in Mechanical Design, $2^{\text {nd }}$ ed., John Wiley and Sons, ISBN: 0471558915, New York

[4] McEvily, A.J. (2002). Metal Failures, John Wiley and Sons, ISBN: 0471414360, New York

[5] Rozvany, G.I.N. (1989). Structural design via Optimality Criteria, Kluwer Academic Publishers, ISBN: 9024736137, London

[6] Dai, X.X. \& Richard Liew, J.Y. (2010). Fatigue performance of lightweight steel-concrete-steel sandwich systems. Journal of Constructional Steel Research, 66, 2 (February 2010), 256-276, ISSN: 0143-974X

[7] Dobrzański, L.A.; Kowalski, M. \& Madejski, J. (2005). Methodology of the mechanical properties prediction for the metallurgical products from the engineering steels using the Artificial Intelligence methods. Journal of Materials Processing Technology, 164-165, (May 2005), 1500-1509, ISSN: 09240136

[8] Portolés, J.M.; Romero, M.L.; Bonet, J.L. \& Filippou, F.C. (2011). Experimental study of high strength concrete-filled circular tubular columns under eccentric loading. Journal of Constructional Steel Research, 67, 4 (April 2011), 623-633, ISSN: 0143-974X

[9] Brnic, J.; Canadija, M.; Turkalj, G. \& Lanc, D. (2010). Structural Steel ASTM A709-Behavior at Uniaxial Tests Conducted at Lowered and Elevated Temperatures, Short-Time Creep Response and Fracture Toughness Calculation. Journal of Engineering Mechanics, 136, 9, (September 2010), 1083-1089, ISSN: 07339399

[10] Brnic, J.; Niu, J.; Canadija, M.; Turkalj, G. \& Lanc, D. (2009): Behavior of AISI 316L steel subjected to uniaxial state of stress at elevated temperatures. Journal of Materials Science and Technology, 25, 2 (March 2009), 175-180, ISSN: 1005-0302

[11] Brnic, J.; Turkalj, G.; Canadija, M. \& Lanc, D. (2009). Creep behavior of high-strength low-alloy steel at elevated temperatures, Materials Science and Engineering A, 499 (January 2009), 23-27, ISSN: 0921-5093

[12] Annual Book of ASTM Standards, Metal Test Methods and Analytical Procedures (2005). Vol 03.01, ASTM International, ISBN: 0803138814, Baltimore

[13] Boresi, A. P., Schmidt, R. J. (2003), $6^{\text {th }}$ ed., John Wiley \& Sons, ISBN: 0471438812 / $0471391387($ WIE), USA

[14] Anderson, T. L. (1995). Fracture Mechanics, $2^{\text {nd }}$ ed., CRC Press, ISBN: 0849342600, New York

[15] Vukelic, G. \& Brnic, J. (2011). Comparison of Materials Fracture Resistance Based on J-criterion. Annals of Daaam for 2011 \& Proceedings of the $22^{\text {nd }}$ International DAAAM Symposium, 23$26^{\text {th }}$ November 2011, Vienna, 22, 1, ISSN: 17269679, ISBN: 9783901509834, Katalinic, B. (Ed.), 1411-1412, DAAAM International Vienna, Vienna

[16] Chao, Y. J., Ward, J. D., Sands, R. F. (2007). Charpy impact energy, fracture toughness and ductile-brittle transition temperature of dual-phase 590 steel, Materials and Design, 28 (2007), 551-557, ISSN: 0261-3069

[17] Roberts, R. \& Newton, C. (1981). Welding Research Council Bulletin, Vol. 265, 1-18, ISBN: 1581452640 